Session \#2559

\title{
Promoting Manufacturing Engineering Technology Programs at the High School and Middle School Levels Using CAD
}

\author{
Radha Balamuralikrishna \& Clifford R. Mirman \\ Northern Illinois University \\ DeKalb, IL 60115, USA \\ Email: bala@ ceet.niu.edu, mirman@ ceet.niu.edu
}

\begin{abstract}
Overview
In an earlier publication, the authors presented a set of ideas advocating the use of computeraided design (CAD) to inspire middle and high school students consider a career in engineering technology through study at a higher educational institution ${ }^{1}$. The approach required the integration of CAD in selected school topics initially through teacher training, and subsequently extending new learning opportunities to students through their teachers. This paper complements the above-mentioned publication, describing new perspectives on the importance of advertising engineering technology programs at the middle and high school levels. The process of creation of a CAD-integrated lesson module that lends itself for high school instruction is discussed. Finally, the importance of a close collaboration between two and four year colleges in making it easier for community college students to pursue a Bachelor's degree program is considered using Northern Illinois University (NIU)'s Manufacturing Engineering Technology program as the model example.
\end{abstract}

\section{Significance of a Proactive Relationship}

Occena et. al. projected that most school students map out their career paths by the time they enter their final year in high school ${ }^{2}$. The increased emphasis on formal education by employers coupled with the simultaneous drop in demand for unskilled labor in the United States continues to motivate high school graduates to pursue a college education, two-year or four year. It is true that things do not always proceed as planned and a large number of students switch career plans, and hence their majors during their college years. However, professional bodies such as the American Society for Engineering Education and the Society of Manufacturing Engineers have embarked on initiatives geared to aggressively promote engineering and technology in K-12 education ${ }^{3,4}$. The rationale behind such campaigns is to "catch them young" and induct the best available high school talent to pursue a career in engineering or technology ${ }^{3}$. ASEE President Jakubowski warned that "if the United States does not start closing the gap in student achievement in science and mathematics, the country runs the risk of becoming disadvantaged in the worldwide economy ${ }^{5, p .41 " ~ H i s ~ p r o f o u n d ~ f a i t h ~ i n ~ t h i s ~ p r o c l a m a t i o n ~ w a s ~ d e m o n s t r a t e d ~ b y ~ t h e ~}$ recent introduction of an initiative called the ASEE Center for Best Practices in K-12 Science and Math Education.

K-12 education has attracted national attention for nearly twenty years, as it became evident that the United States school system was falling behind those of other industrialized nations ${ }^{5}$. 
National, state, local, and even individual citizen based initiatives have emerged in order to reverse the undesirable trend ${ }^{3,6,7}$. Yet, these years of effort do not have much to prove by way of results. Although it is well recognized that the science and mathematics education provided during the K-12 years is important to engineering and technology education, there is virtually no assessment of this scenario, quite possibly due to the lack of sufficient collaboration between high schools and colleges. Science and mathematics education form the backbone for engineering and technology careers; it is essential for engineering and technology educators to step in and collaborate with K-12 teachers in devising more effective and meaningful ways of enhancing the scientific and mathematical capability of school students. Even more importantly, it is necessary to conduct true assessment and measure results achieved due to the implementation of any new initiative.

Engineering and technology programs have long benefited by the presence of certain technical courses or electives included in the middle and high school curriculum. High school courses in design drafting, machining, woodworking, automation, and automobile technology have often sparked student interest and enticed them to pursue careers in technology. However, from our personal observations, there has been an increasing trend on the part of the Northern Illinois regional high schools to cut down on technology programs citing cost of equipment, lack of teachers, and laboratory space requirements as reasons. This translates into more work for colleges seeking to promote engineering and technology among school students.

\section{Interaction with Area Middle and High Schools}

The NIU engineering technology programs are offered in two areas of specialization, Electrical Engineering Technology (EET) and Manufacturing Engineering technology (MET). The efforts described in this paper were directed from the MET program point of view addressing its future direction from the perspectives of student recruitment and community outreach. In this section, we discuss the reasons for our decision to proactively seek new ways of interacting with area middle and high schools.

The Northern and Northeastern Illinois region have historically served as an industrial base for this country. In particular, manufacturing plays a significant role in the region's economy. The two large cities of Chicago and Rockford provide a home for some of the largest and betterknown manufacturers in the nation. It is not surprising that several universities located in and around the region offer degree programs in manufacturing. In addition to NIU, the Illinois Institute of Technology, Illinois State University, University of Wisconsin-Madison, Milwaukee School of Engineering, Western Michigan University, and Bradley University offer degree programs in either manufacturing engineering or MET. Two-year degree programs are far too many to mention. Therefore, it is clear that NIU's Technology department will have to compete with these regional and other institutions in order to build its best possible freshmen class. Further, our experience at NIU suggested that a significant number of students appeared to recognize engineering technology as a field of study only after they have spent a year or two on the college campus. In other words, a significant number of high school students make their initial career choice without having access to key information that would enable them to take advantage of their innate talent and aptitude for technical problem solving. In order to improve the visibility of engineering technology programs, we decided to explore new avenues to reach out to the K-12 community, particularly, middle and high schools. 
The advertisement and promotion of engineering technology in schools can be a win-win situation for both school students and the engineering technology program itself. If a student decides on an engineering technology major at the very start of post secondary education and pursues it with diligence according to the prescribed path, he/she should be able to earn our fouryear degree taking no more than the normal time required completing the program. Transfer students typically take one or two years more to graduate. The informed student therefore is likely to spend less money on tuition, and enter employment much sooner. The resulting immediate monetary benefit can be significant, about or upwards of $\$ 50,000$. If long-term financial benefits and other intangibles such as opportunity cost are considered, timely information becomes even more attractive for the individual student. The academic program in turn benefits through the presence of more motivated, success-driven students in the classroom. Upon graduation, these students are likely to create a significantly better impression on their employers thus enhancing the business and industry perceptions of the institution. Industry support to the program would then likely grow to higher levels and a perpetual cycle of growth and accomplishment can become a reality.

Teachers and career counselors at middle and high schools play a significant role in advocating higher study programs for their graduating students. An informal survey of area schoolteachers and counselors in the Rockford school district revealed that a significant number of these people were unaware of the engineering technology programs at NIU. This implied that there was a need to advertise and involve teachers and counselors in our efforts to make the departmental offerings known to school students. Therefore, it was imperative for the Technology department to seize any opportunity for advertisement, and highlight our distinctive competency in providing a high quality MET educational program that combined theory with practice. In particular, the authors realized that it was important to establish a micro-level working relationship between the department faculty and schoolteachers, where both short-term and long-term collaborative projects are included.

\section{Train the Teacher Initiative}

The authors were invited to serve as consultants in a project that was targeted to promote scientific and technological literacy among middle and high students in the Rockford school district. Serving in this capacity provided the opportunity to employ the following four different but complementary outlets to promote our engineering technology programs, particularly MET:

(1) Conduct a 1-hour general orientation session for approximately 80 schoolteachers describing the manufacturing technology, electrical engineering technology, and industrial technology programs offered by the department

(2) Run a 90-minute career workshop for approximately 60 schoolteachers using a hands-on approach. CAD combined with rapid prototyping was used to provide an insight into modern manufacturing practice and education. The basic idea here was to demonstrate and communicate that Technology department's teaching philosophy is one of combining theory with practice. 
(3) Plan and implement a 2-day CAD skill workshop for approximately twenty schoolteachers designed to provide teachers with initial skills to build confidence and motivate them to consider integrating the use of CAD tools in their current lesson plans.

(4) Prepare an instructional module complete with lesson objectives, presentation material, activities, and assignments to facilitate transfer of CAD skills from schoolteachers to their students.

The first three activities are described in Reference [1]. In this paper, we provide details of the instructional module that was provided to the teachers for study and use in their classrooms. We must reiterate here that the schoolteachers' participation in each activity was on a voluntary basis. During the course of the CAD skill workshop, teachers were asked why they wished to learn this subject matter. Several responses indicated that teachers wished to incorporate CAD in their current lesson plans if possible.

This high level of motivation inherent in the teachers provided the incentive to invest efforts in the creation of a written module to help teachers impart CAD skills to their students. During the past twenty years, CAD has revolutionized design and manufacturing. The modern integrated product and process development paradigm in manufacturing embraces CAD as a powerful enabling technology. Acquiring a basic knowledge and skill in CAD is highly likely to motivate students who possess basic science and math skills to learn more about technology in general. Other reasons justifying the use of CAD in the present context are given in Reference [1].

\section{Description of the CAD Instructional Module}

K-12 education in Illinois schools, much like the schools in the rest of the nation is largely standards-based. State and national standards for student achievement in specific knowledge domains are readily available, and at the Illinois Rockford School district in particular, teachers are expected to teach to standards. The on-line availability of state and national educational standards for each grade level at www.livetext.com rendered the task of writing this module that much easier.

The instructional module consisted of two lessons: Lesson 1 titled "Plane geometry - Creating familiar two-dimensional shapes and estimating areas", and Lesson 2 titled "Employing computer aided design (CAD) to solve problems involving heights and distances." Lesson 1 could be used in either middle or high schools with minor adaptation. Lesson 2 was strictly meant for use at the high school level. CAD was integrated into these lessons as appropriate. The approach was one where simplicity was emphasized. The basic purpose of this module was to introduce students to the technology of computer-aided design making use of mathematical concepts that were typically covered at that particular level of study. Students were required to possess a prior knowledge of applying mathematical formula to compute areas created by enclosed 2-D shapes to complete lesson 1. Also, students should have prior knowledge of solving problems related to heights and distances using the methods of trigonometry in order to complete lesson 2. The module would allow students to experience how computer aided design enabled calculating areas of 2-D shapes and solve typical trigonometry-based problems involving heights and distances through the application of full-scale vector graphics. We reiterate 
that CAD techniques only served to complement and not substitute the conventional analytical techniques using paper and pencil. Prior communication with teachers indicated that they would be willing to invest the extra time and effort needed to incorporate the CAD approach. A brief description of the material in the two lessons will be provided.

Lesson 1 highlights:

The Illinois State educational standards driving the content of lesson 1 were:

IL-6.C Compute and estimate using mental mathematics, paper and pencil methods, calculators and computers.

IL-7.A Measure and compare quantities using appropriate units, instruments, and methods.

IL-7.A.4b Apply formulas in a wide variety of theoretical and practical real world measurement applications involving perimeter, area, volume, angle, time, temperature, mass, speed, distance, density and monetary values.

In this lesson, the students were exposed to the basics of CAD. Although the lesson plan was based on the use of the SilverScreen ${ }^{\mathrm{TM}}$ software, the module can be readily adapted for use with other CAD software including AutoCAD ${ }^{\mathrm{TM}}$. Basic drawing setup commands including an understanding of the toolbars and the drawing editor were included at the outset. Therefore, students could model a two dimensional situation using either the US Customary or the SI units. The lesson further focused on creating regular 2-D shapes such as a triangle, rectangle and circle precisely to specifications both in terms of size and location. The ability to query various aspects of the created geometry such as the length of a line, area of a shape using a software command was emphasized. The lesson quickly proceeded to demonstrate the use of CAD in engineering applications through problems such as: "The largest possible cylindrical disc is stamped from a square metal plate $200 \mathrm{~mm}$ on a side. What per cent of the metal is wasted in this process?"

Finally, we included a set of activities (assignment) to be completed by the students with guidance from their teachers. The learning premise adopted here was that if students followed through the lecture material and completed the example problems, they should have no undue difficulty in completing the assignment problems. Reference [1] includes an assignment problem that required students to calculate 2-D shapes to precise specifications and then get an estimate of areas using CAD. Another assignment problem follows: "The surface of an aluminum metal sheet has the shape of an equilateral triangle. The base measures $525 \mathrm{~mm}$. What is its area? Solve the problem using CAD and state your answer specifying correct units. Also, determine the altitude (height) of the metal sheet in mm." References [8] and [9] proved to be useful resources for the selection of problems in our module.

Lesson 2 highlights:

The Illinois State educational standards driving the content of lesson 2 were: 
IL-7.C.4a Make indirect measurements, including heights and distances, using proportions (e.g., finding the height of a tower by its shadow).

IL-7.A Measure and compare quantities using appropriate units, instruments, and methods.

IL-7.A.4b Apply formulas in a wide variety of theoretical and practical real world measurement applications involving perimeter, area, volume, angle, time, temperature, mass, speed, distance, density and monetary values.

Students should have completed lesson 1 before starting on lesson 2. Complete step-by-step tutorials to solve the following problems that were included as part of teacher presentation material was provided.

1. What is the angle of elevation of a tower 20 meters high from a point 80 meters away?

2. Suppose that an ornithologist is observing birds on a cliff using a pair of binoculars. She is 100 meters from the cliff. Neglecting the height of the ornithologist, find by CAD drawing the heights of the birds being observed when her line of sight makes angles of $15^{\circ}, 30^{\circ}, 45^{\circ}$ and $60^{\circ}$ with the horizontal.

3. A surveyor standing $50 \mathrm{~m}$ from a cooling tower measures the angle of elevation of the top as $31^{\circ}$. What is the height of the tower if the measuring instrument itself is $1.5 \mathrm{~m}$ above the ground?

The following assignment problems were included with the expectation that students would solve with minimal guidance from their instructor:

1. A boy of height $1.75 \mathrm{~m}$ is measuring the heights of trees in the school grounds. He stands 24 meters from a tree and measures the angle of elevation as $42^{\circ}$. Calculate the height of the tree (from ground level to treetop) as accurately as possible.

2. A tree located at a distance of 20 meters from a house is being chopped down. The angle of elevation of the top of the tree as measured from a first floor window is $44^{\circ}$. Is it safe for the tree to fall in the direction of the house?

3. At a certain time during the day, the shadow (on the ground) of a vertical 75 feet pole is 100 feet long. What is the angle of elevation of the sun?

The reader will notice that the problems included in the module encompass various levels of mental stimulation as defined in the Bloom's taxonomy of learning including knowledge, application, analysis, and synthesis. 


\section{Community College/NIU Articulation Agreement}

For many high school graduates, community colleges provide a bridge from their high school diplomas to a four-year college degree. The Technology department strongly believes in working with area community colleges. The following table shows a typical model for articulation between the community college and the NIU Department of Technology. The programmatic articulation between the community college is a very difficult and delicate agreement. In general, both entities have their own needs and constituent groups that must be provided for by the curricular offerings. In some instances, like the one shown in the Table 1, several programs are included in the agreement, and each program is handled in different modes. A single program from the community college level can satisfy two programs at the University level, and the students are explained the how and why of this articulation. In general, the Community College students fulfil 66 hours of credit to obtain the AAS degree. Depending upon the program of choice at the University level, some of these credits will apply. The goal of the articulation is to determine and present which of the courses will apply. With the existing framework in Table 1, the NIU Technology Department continues to work with the regional Community College to fit more courses into the articulation agreement. Since this agreement is in the best interests of both parties, they will work together within the curriculum framework of both institutions, to present the most favorable articulation agreement to seamlessly transfer courses.

\section{Conclusion}

In an era of global competition, an better-educated and trained workforce will separate the winners from the losers. The future of America depends to a great extent on its current K-12 student population. The quality of engineers and technologists produced in this country cannot help but have a strong positive correlation with the quality of science and mathematics education provided by K-12 education, particularly middle and high school. In the interest of the nation, it is important to recognize the need for an interdependent relationship between college faculty and schoolteachers, and their institutions. Through more interactions at micro-levels of school education, these two groups can work together to integrate more engineering and technical applications in high school science and math subjects at optimal levels. It is important that new initiatives undergo rigorous assessment procedures so that results can be measured.

The Technology department at NIU is proud of its role in the initiative presented in this paper. The feedback from the Rockford area schoolteachers and counselors has been very positive. Future plans are to include more teachers in the program and open more channels for dialogue and communication between department faculty and schoolteachers. We also plan to develop more lesson modules that incorporate other engineering technology principles, and embed computer tools in teaching school science and mathematics. This also means that we have to explore new ways to finance the outreach activities we visualize. From our viewpoint, investing to establish a meaningful college-school relationship is expensive; however, not doing so could prove even more expensive to the department and our community as a whole. Further, we will assess the effectiveness of our outreach efforts to help us better decide how future resources should be allocated in our collaborative efforts with middle and high schools.

\section{Acknowledgment:}

The authors thank Dr. Jule D. Scarborough, Director for the Rockford Scientific Literacy project mentioned in this paper for providing us with an opportunity to work as consultants. 
SilverScreen $^{T M}$ is a trademark of Schroff Development Corporation.

AutoCAD $\boldsymbol{D}^{T M}$ is a trademark of Autodesk Inc.

Table 1. A work-in-progress course articulation agreement between NIU's technology department and an area community college

\begin{tabular}{|c|c|c|c|}
\hline & & & dits \\
\hline & & MET & IT \\
\hline RVC & NIU & Program & Program \\
\hline Major area of study & & & 23 \\
\hline CDT 103 & & & \\
\hline CDT 104 & Tech 265 & 3 & 3 \\
\hline CDT 110 & & & \\
\hline CDT 133 & & & \\
\hline CDT 141 & & & \\
\hline \begin{tabular}{|c|} 
CDT 142 \\
\end{tabular} & & & \\
\hline \begin{tabular}{|c|} 
CDT 146 \\
\end{tabular} & none & & \\
\hline CDT 211 & TECH 404 & 3 & 3 \\
\hline CDT 219 & $\begin{array}{l}\text { TECH } 310 \text { and } 369 \text { if split in two } \\
\text { courses and material added (note: } 3 \\
\text { credits now - could be } 6 \text { in future) }\end{array}$ & 3 & \\
\hline CDT 143 & -Tech 342 & 3 & \\
\hline CDT 220 & flecn 342 & 3 & \\
\hline \begin{tabular}{|l|} 
CDT 221 \\
\end{tabular} & Tech Process elective & 3 & \\
\hline \begin{tabular}{|l|} 
CDT 222 \\
CDT162
\end{tabular} & & & \\
\hline $\begin{array}{l}\text { CDT162 } \\
\text { or } \quad \text { EET } 220\end{array}$ & none - Change to meet the TECH & & \\
\hline or EET 220 & 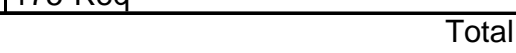 & 15 & 29 \\
\hline Gen Ed REQUIREMENTS - & off of the transfer list & & \\
\hline ENG 101 & ENG 103 & 3 & 3 \\
\hline OR ENG 103 & & & \\
\hline OR ENG110 & & & \\
\hline OR ENG 105 & & & \\
\hline OR SPH 131 & COMS 100 & & \\
\hline OR SPH 141 & & & \\
\hline MTH 125 & MATH 155 & 3 & 3 \\
\hline OR MTH 100 & NONE & & \\
\hline PHY 112 & NONE & & \\
\hline OR CHM101 & CHEM 210 & 3 & 3 \\
\hline OR GES101 & NONE IN EET PROGRAM & & \\
\hline CIS 102 & & 0 & 0 \\
\hline One Gen Ed cour & $\mathrm{h}$ is part of IAI & 3 & 3 \\
\hline & Total & 12 & 12 \\
\hline & Total Transfer as of $6 / 20 / 01$ & 27 & 41 \\
\hline
\end{tabular}




\section{References}

(1) Balamuralikrishna, R. \& Mirman, C. R. (2002, January 6-8). Motivating high school and middle school students towards careers in CAD. Proceedings of the $56^{\text {th }}$ Annual Mid-Year Conference of the Engineering Design Graphics Division, American Society for Engineering Education, Berkeley, CA.

(2) Occena, L.G., Chen, C. H., \& Lammers, B. M. (1996, March 13-15). CMIEE: An investment in future manufacturing engineers. Proceedings of the International Conference on Education in Manufacturing, San Diego, CA.

(3) Cohen, W. (2001). Role model for diversity. ASEE Prism, 11(3): 30-34

(4) Hogan, B. J. (Editor) (2001, October). News desk - Engineering competition, Manufacturing Engineering, 127(4): 23

(5) Jakubowski, G. (2002). Is there a role for ASEE in K-12 education? ASEE Prism, 11(5): 41.

(6) Cummings, M. (2001). The media is the message. ASEE Prism, 11(3): 68

(7) Mathias-Regel, B. (2001). Early to engineering. ASEE Prism, 11(2): 45

(8) Schaaf, W.L. (1963). Mathematics for everyday use. Revised edition. Garden City, NY: Dolphin Books, Doubleday and Company, Inc.

(9) Bowie P.G. [Editor] (1969). The School Mathematics Project. Book 4 (Metric). London, Great Britain: Cambridge University Press.

\section{Biographical Information}

DR. RADHA BALAMURALIKRISHNA joined the Department of Technology at NIU in August 1997. His undergraduate degree is in Naval Architecture and Shipbuilding from Cochin University, India. Dr. "Bala" has worked in a shipyard for three years and has taught engineering design graphics and CAD at the University level for nearly 10 years. He received his M.S. Eng. from Florida Atlantic University and Ph.D. from Iowa State University.

DR. CLIFFORD R. MIRMAN received his Ph.D. degree from the University of Illinois at Chicago in 1991. He is currently the Chair of the Department of Technology at Northern Illinois University. He is active in the areas of $\mathrm{CAD}$, finite-element-analysis, and kinematics, both securing grants and writing publications. Dr. Mirman is actively involved in the American Society of Engineering Education (ASEE) and Society of Manufacturing Engineers (SME). 